\title{
Modelo de projeto para a gestão territorial em responsabilidade socioambiental quântica: a integração comunidade, universidade e sociedade civil
}

\section{Luís Henrique Ramos de Camargo}

Universidade Estadual do Rio de Janeiro. Faculdade de Educação da Baixada Fluminense. Departamento de Geografia. Laboratório de Geografia. Rua Gal. Manuel Rabelo, s/n. Vila São Luiz. Duque de Caxias-RJ, Brasil (CEP 25065-050). E-mail: geocamargo@ig.com.br.

Resumo. Visando a gerar um modelo de gestão territorial que possa ser aplicado na prática da responsabilidade socioambiental apresentamos à comunidade científica uma metodologia que se baseia nos princípios filosóficos advindos da mecânica quântica. Esta gestão não se limita a pensar o lugar da pesquisa a partir de fragmentos e sim de sua totalidade em sua complexidade que será analisada a partir de uma rigorosa ação científica. Para a compreensão deste processo espaço-temporal, neste texto será feito um pequeno debate conceitual e um resumo da gestão. Este projeto foi aplicado em trabalhos de campo ao longo dos últimos 15 anos, representou a Universidade Estadual do Rio de Janeiro na Rio+20 e foi considerado excelente pelo Departamento de Extensão, da Universidade Estadual do Rio de Janeiro (DEPEXT/UERJ). Pensando em formar uma rede de negócios ecológicos em comunidades carentes, este mecanismo espaçotemporal pretende sua expansão exponencialmente em diferentes lugares propiciando valores universais, qualidade de vida e uma nova postura a frente dos antigos paradigmas econômicos.

Palavras-chave: Quântica; Espaço-tempo; Gestão territorial; Complexidade.

Abstract. Project model for territorial management in quantum socio-environmental responsibility: The integration of community, university and civil society. In order to generate a territorial management model that can be applied in the practice of socio-environmental responsibility, we present to the scientific community a methodology that is based on the philosophical principles arising from quantum mechanics. In this sense, management this project is not limited to thinking the place of research from fragments, but from its totality in its complexity, which will be analyzed from a rigorous scientific action. In order to understand this spatio-temporal process, a short conceptual debate and a summary of the management project will be made in this text. This project was applied in field
Recebido

$15 / 07 / 2020$

Aceito

$02 / 10 / 2020$

Disponível on line

$03 / 10 / 2020$

Publicado

$31 / 12 / 2020$

Acesso aberto

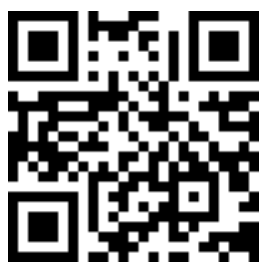

ORCID

D) 0000-0002-2604-7128 Luís Henrique Ramos de Camargo

ISSN 2359-1412/RBGAS-2020-0107/2020/7/17/4/1101

Rev. Bras. Gest. Amb. Sustent.

http://revista.ecogestaobrasil.net 
work over the last 15 years, represented the Universidade Estadual do Rio de Janeiro (UERJ) at Rio+20 and was considered excellent by Departamento de Extensão, of the Universidade Estadual do Rio de Janeiro (DEPEXT/UERJ). Thinking of forming a network of ecological businesses this space-time mechanism intends to expand exponentially in different places, providing universal values, quality of life and a new posture in front of the old economic paradigms.

Keywords: Quantum; Space-time; Territorial management; Complexity.

\section{Introdução}

Este texto, que também faz parte de pesquisa desenvolvida como estágio Pós Doutoral na UFRJ, tem o objetivo de apresentar à comunidade uma pequena exposição, fruto de uma sequencia de buscas literárias e experimentais, que remete ao campo da gestão territorial socioambiental e dos caminhos necessários para sua excelência.

Dando continuidade à paixão desenvolvida de quando universitário pela questão ambiental desenvolvemos uma trajetória neste campo que foi da especialização, passando pelo mestrado, chegando ao doutorado e mais recentemente ao pós-doutorado.

Paralelamente a esses estudos, outra dinâmica de aprendizado se fez presente, fato propiciado pela coordenação de monografias ligadas ao terceiro setor em um Curso de Administração de Empresas da Universidade Estácio de Sá (UNESA). Nesta coordenação, aprofundamos a leitura em torno da relação da empresa com outras possibilidades de rentabilidade e consequentemente de lucratividade ligadas às ações sociais e ambientais.

Em 2005, quando ingressamos na Universidade Estadual do Rio de Janeiro (UERJ), na possibilidade de termos uma atividade de extensão acadêmica, foi criado "A Geopolítica da Natureza", projeto que se dedicou a compreender como um mecanismo de analise espacial (ambiental) pode ocorrer na prática; mais tarde, em outra etapa da universidade reiniciamos uma dinâmica parecida nas comunidades do Cantagalo, localizada em Ipanema, no Rio de Janeiro, e no ano seguinte no Pavão-Pavãozinho, localizado em Copacabana, também no Rio de Janeiro. Em 2016, já com o nome de Razão Social, fomos a Parada Morabi, localizada no Município de Duque de Caxias, Rio de Janeiro. Aqui, surgiu a ideia dos comitês de pesquisa, e, por último, iniciou-se um projeto no Quilombo Camorim, localizado em Jacarepaguá, também no Rio de Janeiro.

Como projeto de extensão, já foi considerado excelente pelo Departamento de Extensão, da Universidade Estadual do Rio de Janeiro (DEPEXT/UERJ), representou a Universidade Estadual do Rio de Janeiro (UERJ) na Rio+20; foi citado em diferentes meios midiáticos, foi acolhido pela gestão de Carlos Eduardo Pereira, ex-Presidente do Botafogo de Futebol e Regatas e escolhido como projeto social da gestão. Está registrado como um macro projeto socioambiental no Escritório de Direitos Autorias do Rio de Janeiro, sob número 022774 (Camargo, 2015).

0 projeto que apresentaremos tem como objetivo eliminar a fome e a miséria a partir do reordenamento territorial. Outro objetivo que buscamos com esta pesquisa é repensar a ISO 26000 (ABNT, 2010) para que a mesma não seja apenas um modelo a ser seguido em seus fragmentos, mais que tenha uma metodologia quântica própria. 


\section{Debate teórico}

\section{Jung e o inconsciente coletivo}

Ao longo desta jornada aprendemos que é possível trazer dignidade e cidadania aos invisíveis da sociedade. A participação comunitária integrada a agentes externos incluindo a universidade tende a resultar em positividade. E, a partir de experiência adquirida, acreditamos que o caminho metodológico bem traçado é o diferencial para que essa associação funcione.

Neste sentido traçamos como diferencial inicial a busca do apoio de setores específicos da sociedade (sintropia positiva). Assim, adotamos a proposta de Kelly (2016) de integração triangular envolvendo ativos sociais (universidade), comunidade e ativos tecnológicos. Os ativos tecnológicos possibilitam a integração com investidores, que passariam a ser steakholders.

Esta associação sintrópica positiva tem como objetivo plantar a semente do endodesenvolvimento de forma a eliminar a fome e a miséria a partir da gestão do território. No sentido de encontrar a estratégia ideal para resolver essa demanda, optamos pela bagagem filosófica ligada à mecânica quântica. Essa opção se relaciona a compreensão da inerente complexidade que envolve tanto a dinâmica da Natureza como da sociedade.

Questões como a experiência de Copenhagem, o paradoxo Einstein-PodolskyRosen, a desigualdade de Bell e a incerteza em Heisenberg, por exemplo, tem muito a nos ensinar a respeito do porvir e do vasto oceano das possibilidades futuras. A Natureza vem demonstrando ser auto-organizada e ligada à complexidade, a não linearidade e a diacronia se associam ao imprevisível que vem quebrando os antigos padrões sequenciais tanto ambientais quanto sociais.

Não é possível que as ciências sociais e ambientais, ainda sejam prisioneiras das limitações que norteiam a epistemologia clássica. Khun (1970) em seu clássico "A Estrutura das Revoluções Científicas" ensina que quando um paradigma científico não funciona mais para explicar a realidade ele deve ser substituído. Porém, a questão não é tão simples.

A leitura da realidade cartesiana-newtoniana-baconiana além de ser ensinada na escola como sendo a própria Physis, norteou o sentido de realidade das gerações passadas que educou as atuais gerações. Portanto a lógica clássica não é apenas um modo frio e mecânico de se ver a vida, este paradigma participa da construção constante e dialética de nosso imaginário de realidade.

Provavelmente está forma de conceber a physis se encontra no inconsciente coletivo (Jungiano) da sociedade. O conceito de inconsciente coletivo em Jung (18751961), de forma diferente de Freud (1856-1939), acredita que por sermos um conjunto social apresentamos vínculos que partilhamos com a sociedade (Jung, 1980). Para Jung (1980) o inconsciente coletivo, guarda impressões herdadas pela família e indivíduos de fora. É nele que estão às ideias pré-concebidas e que acabam sendo algo que não conhecemos de nós mesmos, e que em geral, caminham para fazer parte de nossas vidas.

Esta forte e inerente dialética desenvolve um grande consenso coletivo, aonde cada indivíduo recebe de forma passiva e integrada uma herança clássica moldando a percepção da realidade a essa lógica. E como o desenvolvimento sustentável envolve a relação entre a Natureza e a sociedade integradamente, como epistemologicamente construir uma metodologia sem compreender a realidade em sua complexidade e imprevisibilidade?

\section{0 planeta Terra}

A opção pela bagagem quântica está relacionada à própria dinâmica interna apresentada pelo planeta. A Terra é um macrosistema constituído de diferentes 
subsistemas regidos pelas suas interações (Drew, 2002). E, segundo diferentes autores como Prigogine e Stengerls (1984, 1997), Prigogine (2008) e Atlan (1992), são essas interações responsáveis pela criação do novo e pelo rompimento de antigos padrões de organização.

Esta característica norteia a interdependência das "partes" que formam o conjunto do planeta apresentado conexão total, de forma direta ou tênue, sendo impossível "compreender" qualquer aspecto isolado sem referencia à sua função como parte do conjunto maior (Capra e Stendl-Rast, 1991; Drew, 2002).

Nesta dinâmica, envolvendo a toda Terra, as quatro grandes esferas (hidrosfera, litosfera, atmosfera e biosfera) desenvolvem entre si trocas constantes, o que segundo Vitte e Dutra-Gomes (2019) sugerem, pela sua complexidade, uma dinâmica que está na gênese do movimento e do nascimento de novas realidades geossistêmicas no planeta.

A dinâmica de trocas na Terra, que envolve sociedade-Natureza, NaturezaNatureza é o que impulsiona o movimento de transformação e mudança. É como o ying em contato com o yang gerando o novo, o Tei-Gi em movimento em busca do Tao (Lao-Tsé, 2004).

O planeta, a cada aumento de complexidade evolui em espiral, saindo de uma totalidade a1, para uma totalidade a2, e isso ocorre, pois a totalidade sempre é superior ao somatório de suas partes, ou seja, a evolução é constante (Santos, 1997b).

Cada subsistema possui uma singularidade própria, aonde a dinâmica de suas variáveis ao se encontrarem com outro sistema, que também é singular, gera desordem, o que posteriormente se reordena em uma nova ordem, porém com singularidade própria (Morin, 1977).

Aí se encontra a mudança, o movimento, que pode ser compreendido na leitura, por exemplo, dos processos em Whitehead (1930). Esse movimento devido a sua característica diacrônica e que não segue uma flecha linear, pode ser compreendida a partir do contexto da experiência de Copenhagem e não em uma leitura clássica.

Esses encontros que geram ruído podem apresentar irreversibilidade, isso é muito comum em escalas como os solos nos casos de voçorocas, nos biomas que se desertificaram dentre outros fenômenos naturais. 0 mecanismo de aumento de complexidade é internamente um processo constante de quebra de padrões e de reconstrução de novos patamares de organização.

Ocorre que, encontros sintrópicos de baixa magnitude, como em uma prática na agrofloresta, provocam muito menos "ruído" do que uma grande área desmatada para agricultura intensiva. No caso dessa agricultura, Drew (2002) menciona que o maquinário, a irrigação artificial, os pesticidas e fertilizantes, são energias externas que além, de diminuir a produtividade do ecossistema, ainda provocam grande desequilíbrio no meio natural.

Estamos a cerca de 10 mil anos, desde o início do neolítico desmatando grandes áreas para pastagem, plantio, moradia dentre outras questões, e associado a isso, centenas de intervenções no equilíbrio da dinâmica terrestre aconteceram propiciando muitos mecanismos de reorganização a partir do "ruído" (Atlan, 1992).

Sendo um macrosistema, o planeta submete-se às leis da Natureza. Um sistema pode estar em estado de equilíbrio dinâmico, em equilíbrio de resistência, em estagio de resiliência ou o mesmo pode romper com seu antigo padrão, buscando novos sistemas de organização espaço-temporal (irreversibilidade) (Camargo, 2005).

Nosso planeta estaria em que estágio de evolução dinâmica de seu atual padrão de organização atmosférico-geológico-ecológico?

\section{0 espaço absoluto e a totalidade em totalização (espaço-tempo)}

Para Newton (1987), o tempo era absoluto, verdadeiro e matemático fluindo sempre por si mesmo, sem relação com coisa externa alguma; bem como o espaço 
absoluto, também sem nenhuma relação externa permaneceria sempre imóvel e semelhante, portanto repetitivo e preso a antigos padrões que garantem ao habitante da Terra a ideia de estabilidade (Davies, 1999; Smilga, 1966).

Kant (1999), que foi grande leitor de Newton, trazia a ideia de que o espaço é uma representação dada a priori, portanto, que apenas existia em nossa percepção da realidade. Essa visão de espaço absoluto reflete como o espaço era visto: um grande receptáculo tridimensional e inerte, assim como um palco vazio de teatro. 0 tempo por sua vez, também sem influencia externa corria seu fluxo linearmente.

Por sua vez, a partir das pesquisas de Minkowski (1864-1909) em seu continuum do espaço-tempo e da Teoria da Relatividade de Einstein (1879-1955), o conceito de tempo e de espaço sofre uma brusca alteração (Smilga, 1966). Hawking (2015) ensina que a relatividade geral combina a dimensão temporal com as três dimensões do espaço para formar o que se denomina espaço-tempo trazendo outra forma de se perceber a realidade.

\section{O espaço como método}

Santos (1997b) nos mostra que o espaço é a interconectividade geral entre o sistema de ações (tempo) e o sistema de objetos (que se situam em um determinado e singular espaço).

Buscando compreender a dinâmica espaço-temporal, a gestão bebe nas fontes de três questões em Santos (1997a, 1997b). A primeira remetendo a ideia de que o espaço pode ser compreendido analiticamente a partir das suas categorias: Forma, Processo, Estrutura e Função; em segundo lugar, que o espaço é uma totalidade em constante evolução por totalização (aumento de complexidade) (a totalidade é sempre superior ao somatório interno de suas partes); e em terceiro lugar a compreensão em Santos (1997a) e Moreira (1982) de que o espaço, ou a totalidade em totalização é constituído por diferentes instâncias: jurídicas, econômicas, históricas, etc.

Nesse sentido, além de analisar o espaço e sua evolução no tempo de forma interconectada e analítica, podemos subdividir o mesmo em diferentes instâncias, que por sua vez serão totalidades em totalização. E isso se torna possível a partir dos respectivos comitês de pesquisa que fazem parte do projeto e da gestão.

Os comitês, a partir do conhecimento prévio da região, terão a função de abraçar a realidade dentro de suas características específicas visando a desvendar analiticamente seus principais problemas e virtudes. Assim, nas reuniões de grupo será realizado um monitoramento da evolução de cada pesquisa por comitê buscando sua interpretação à luz da totalidade para a compreensão de sua totalização.

\section{Métodos e metodologia}

\section{Princípios}

A meta desta gestão, independente da escala da região a ser pesquisada, se encontra na efetiva mudança positiva dos lugares. Neste sentido propomos alguns pressupostos organizacionais que orientem nosso objetivo. Estes princípios devem constar da espinha dorsal deste mecanismo e são os seguintes: Planejamento estratégico e participativo (comunidade, sociedade civil e universidade); monitoramento da realidade a partir da consulta constante da comunidade envolvida; busca de inovação tecnológica de baixo custo; geração de emprego e renda; integração do local com o global; Respeito às regras do Estado; Desenvolvimento sustentável que esteja preparado para a complexidade e a auto-organização inerente à relação sociedade-Natureza.

\section{Metodologia}

Em síntese o projeto se desenvolve em uma pré-fase e quatro fases que interagem e se completam. É importante lembrar que este projeto tem o objetivo de se expandir em 
outras regiões geográficas permitindo a constituição de uma grande rede quântica de produtos ecológicos comunitários.

\section{Pré-fase}

Definição dos instrumentos: análise dos meios requeridos (financeiros, organizacionais, legais e de recursos humanos); análise das possíveis fontes e recursos, programas, workshops propostos e etapas do projeto; análise da pertinência e adequação do lugar escolhido; análise da viabilidade financeira; contratação dos estagiários.

\section{1 a fase - Pesquisas prévias, estagiários e contato com a comunidade}

Objetivos: - Pesquisa bibliográfica e iconográfica; mapeamento e subdivisão por diferenciação de áreas (a partir da variável escolhida);

- Negociação política junto à região escolhida (associação de moradores, escolas, etc).

Este projeto desde sua fase inicial buscará um debate junto à comunidade estudada em torno da importância e da compreensão de como o desenvolvimento local é possível e quais diferentes estratégias podem ser desenvolvidas.

Propõe-se assim, nessa fase estabelecer as bases para o modelo de governança apresentado por Kelly (2016).

\section{Comitês de pesquisa}

\begin{tabular}{|l|l|}
\hline Comitê & Geomorfologia, prevenção de erosao, enchentes e deslizamentos. \\
\hline Padrinho & $\begin{array}{l}\text { LAGESOLOS - UFRJ sob a orientação do Prof. Dr. Antônio José Teixeira Guerra - } \\
\text { Coordenador do LAGESOLOS (Laboratório de Geomorfologia Ambiental e } \\
\text { Degradação dos Solos) - Pesquisador 1A do CNPq - CNPq senior researcher. }\end{array}$ \\
\hline Função & $\begin{array}{l}\text { Pesquisa de campo, campanha de prevenção de enchentes e de acidentes como } \\
\text { deslizamento de encostas dentre outros processos ambientais de risco; } \\
\text { responsável por toda análise física em relação ao ambiente. Os exames serão } \\
\text { realizados em laboratórios da Universidade Federal do Rio de Janeiro (UFRJ). }\end{array}$ \\
\hline Estagiário & 1 \\
\hline
\end{tabular}

\begin{tabular}{|l|l|}
\hline Comitê & Saúde e Meio Ambiente (qualidade da água e do alimento). \\
\hline Padrinho & Em aberto. \\
\hline Função & $\begin{array}{l}\text { Estudo das condições ambientais (biogeográficas) na escala local buscando suas } \\
\text { relações com a possibilidade de propagação de doenças, exame de possíveis } \\
\text { vetores, etc.; pesquisa e monitoramento constante da qualidade da água e dos } \\
\text { alimentos; } \\
\text { Atenção especial à nutrição infantil; Saúde - conscientização de ameaças à saúde } \\
\text { como HIV-AIDS, câncer, malária, tuberculose e obesidade; dentre outras doenças. }\end{array}$ \\
\hline Estagiários & 2 \\
\hline
\end{tabular}

\begin{tabular}{|l|l|}
\hline Comitê & Administração, Economia, Desenvolvimento e Captação de Recursos. \\
\hline Padrinho & Em aberto. \\
\hline $\begin{array}{l}\text { Função } \\
\text { (resumo) }\end{array}$ & $\begin{array}{l}\text { Administração básica junto ao CEO; Captar steakholders, verificar editais; pensar } \\
\text { a metodologia para o desenvolvimento local; estudo aprofundado de Ostrom } \\
\text { (1990) como princípio para microeconomia do lugar e adaptação as categorias } \\
\text { analíticas de Santos (1997a; 1997b); Geração de emprego e capacitação (atenção } \\
\text { especial em grupos vulneráveis). }\end{array}$ \\
\hline Estagiários & 3 (Geografia, Economia e Administração). \\
\hline
\end{tabular}




\begin{tabular}{|l|l|}
\hline Comitê & Geohistória, Identidade e Mídia. \\
\hline Padrinho & Em aberto. \\
\hline Função & $\begin{array}{l}\text { Estudar a identidade local como fator de resistência e luta; Trazer a ideia da } \\
\text { importância da descentralização a luz da globalização que tende a diminuir a ação } \\
\text { do Estado permitindo que repasse para a sociedade local a autonomia e o poder } \\
\text { decisório; desenvolver mídia do projeto. }\end{array}$ \\
\hline Estagiários & 1 \\
\hline
\end{tabular}

\begin{tabular}{|l|l|}
\hline Comitê & Direito Ambiental e DDHH e Mídia. \\
\hline Padrinho & Em aberto. \\
\hline Função & $\begin{array}{l}\text { Trazer para a comunidade o debate em torno de temas relativos aos Direitos } \\
\text { humanos; discutir e levantar os problemas ambientais locais; verificar os direitos } \\
\text { básicos do cidadão em sua comunidade como observado pela ONU e pela } \\
\text { Convenção de San Juan; assistência jurídica no projeto. }\end{array}$ \\
\hline Estagiário & 1 \\
\hline
\end{tabular}

\begin{tabular}{|l|l|}
\hline Comitê & Educação Física. \\
\hline Padrinho & Em aberto. \\
\hline Função & $\begin{array}{l}\text { Envolvimento e desenvolvimento da comunidade; Inicialmente pretende-se } \\
\text { estabelecer um elo com a comunidade com ginástica para terceira idade e } \\
\text { exercícios comunitários; posteriormente outras lógicas desportivas podem se } \\
\text { ligar ao projeto o que pode incluir o interesse em formação de atletas em } \\
\text { diferentes áreas do esporte. }\end{array}$ \\
\hline Estagiário & 1 \\
\hline
\end{tabular}

\begin{tabular}{|l|l|}
\hline Comitê & Geoprocessamento e Mapeamento. \\
\hline Padrinho & $\begin{array}{l}\text { Laboratório de Geoprocessamento, da Universidade Federal Fluminense } \\
\text { (Ciências Ambientais). }\end{array}$ \\
\hline Função & Mapeamento e geoprocessamento de todos os dados levantados. \\
\hline Estagiário & 1 \\
\hline
\end{tabular}

\begin{tabular}{|c|c|}
\hline Comitê & Pedagogia e Mídia. \\
\hline Padrinho & Em aberto. \\
\hline Função & $\begin{array}{l}\text { Desenvolver material nas seguintes áreas: Declaração de Copenhagen, Declaração } \\
\text { do Milênio da ONU, Declaração da ONU sobre Meio Ambiente e Desenvolvimento, } \\
\text { Declaração Universal dos Direitos Humanos; Estimulo à educação em todos os } \\
\text { níveis, erradicação do analfabetismo; buscar convênios; Promoção de } \\
\text { oportunidades de aprendizagem para grupos vulneráveis e discriminados; } \\
\text { Promoção de atividades culturais, reconhecimento e valorização das culturas } \\
\text { locais; Estimulo e apoio a voluntários; Educação do consumidor (cartilhas para a } \\
\text { comunidade e convite para debates a respeito do direito do consumidor); montar } \\
\text { folders e material para contato com a comunidade; organização do curso na } 3^{\text {a }} \\
\text { fase. }\end{array}$ \\
\hline Estagiários & 2 \\
\hline
\end{tabular}

\begin{tabular}{|l|l|}
\hline Comitê & Permacultura \\
\hline Padrinho & Em aberto \\
\hline Função & $\begin{array}{l}\text { Desenvolvimento tecnológico e apoio às tecnologias alternativas; Geração de } \\
\text { emprego e renda; desenvolvimento de Programas de empreendedorismo; } \\
\text { Geração de emprego e renda. Geração de horta comunitária e outros produtos; } \\
\text { qualificação. }\end{array}$ \\
\hline Estagiário & 1 \\
\hline Profissional & 1 \\
\hline
\end{tabular}


fotos

\section{$2^{\text {a }}$ Fase - zoneamento, aplicação de questionários por comitês e arquivo de}

Esta fase da pesquisa pode se considerar como mista ou quali-quantitativa, tendo em vista que o pesquisador integrará o quantitativo ao qualitativo a partir do levantamento de dados e de sua análise que buscará a compreensão dos dados a partir de métodos pertencentes à Geografia humanista.

Nesta fase o estagiário em contato direto com a comunidade, e, com o apoio da mídia buscara interagir com o morador, principalmente com a terceira idade, visando à sua percepção a respeito das transformações que o espaço sofreu ao longo do tempo (espaço-tempo) (Geografia da percepção).

Neste sentido os comitês de pesquisa irão aplicar questionários na comunidade a partir de metas pré-estabelecidas e cientificamente estruturadas. Os dados levantados serão graficamente organizados possibilitando o processo analítico do comitê, e em outro momento, do debate que envolverá todos os comitês.

Objetivos: Zoneamento econômico-ecológico e subdivisão das áreas a serem pesquisadas; Aplicação de questionários e formação do arquivo de fotos permanente pelos comitês de pesquisa, análise gráfica e qualitativa; filmagens e reuniões.

\section{O zoneamento econômico-ecológico}

Zoneamento econômico-ecológico da área a ser pesquisada. Lei no 6.938/1981 (Brasil, 1981). Neste caso, será adotada metodologia adaptável à coerência das teorias do espaço geográfico e do campo quântico a partir do MMA no documento Diretrizes Metodológicas para o ZEE do Território Nacional, tendo em vista que o Decreto $\mathrm{n}$ o 4.297/2002 (Brasil, 2002) regulamenta o art. 9o da Política Nacional de Meio Ambiente, estabelecendo critérios para o ZEE do Brasil (MMA, 2019).

Em geral, o mapeamento se encontra na escala de 1:100.000, tendo em vista que a mesma serve para indicativos operacionais de gestão e ordenamento territorial, tais como, planos diretores municipais, planos de gestão ambiental e territorial local, uso de áreas de preservação permanente, nos termos do art. 4º da Lei no 12.651/2012 (Brasil, 2012).

\section{técnico}

$3^{\text {a }}$ fase - Curso de formação de agentes ambientais comunitários - nível

Objetivo: curso profissionalizante; palestras e aulas dadas para a comunidade.

Formação de 25 pessoas (20 locais e 5 não locais) capacitados (UERJ) para a produção e os negócios ecológicos; criação do alicerce teórico que embasará o futuro da rede de negócios ambientais. Essas pessoas deverão ser redistribuídas nas sub-regiões locais.

O número de participantes é relacional ao lugar.

O curso pode ser on-line, semi-presencial ou presencial. Porém, propomos que não seja puramente on-line.

O curso terá a duração de $32 \mathrm{~h}$ distribuída em quatro meses divididos em dois ciclos. 0 básico onde prevalecerão matérias gerais e o profissionalizante com matérias voltadas para a produção e negócios. Cada ciclo terá dois meses.

Principais assuntos a serem debatidos: geração de biomassa e alternativas energéticas, gestão da bacia hidrográfica e de sua rede, Ecologia Política, geohistória e identidade do lugar; condições físicas do lugar (geomorfologia, pedologia, geodiversidade); a permacultura priorizará o debate em torno de três questões: usinas de reciclagem de lixo, hortas comunitárias e fossas ecológicas, porém outros assuntos podem ser também debatidos em sala de aula como: resíduos sólidos e sua redução, biogás, energias alternativas, dentre outros. 


\begin{tabular}{|c|c|}
\hline Matérias & Ementa \\
\hline $\begin{array}{l}\text { EAQ - Educação Ambiental e Qualidade do meio } \\
\text { Ambiente }\end{array}$ & $\begin{array}{l}\text { Relação entre os problemas ambientais } \\
\text { levantados na comunidade. Base no Programa } \\
\text { Nacional de Educação Ambiental. }\end{array}$ \\
\hline EP - Ecologia Política e Organização Comunitária & $\begin{array}{l}\text { Os grandes congressos ambientais, } \\
\text { Ecodesenvolvimento, sustentabilidade etc. }\end{array}$ \\
\hline TA1 - Tecnologias Ambientais 1 & $\begin{array}{l}\text { Hortas comunitárias; geração de energia da } \\
\text { biomassa; redução de resíduos de esgoto, } \\
\text { xampu e sabonete ecológico. }\end{array}$ \\
\hline DDHH - Direitos Humanos & $\begin{array}{l}\text { Debate sobre as normas da ONU e do Congresso } \\
\text { de San Jose. }\end{array}$ \\
\hline TA2 - Tecnologias Ambientais 2 & $\begin{array}{l}\text { Reciclagem de lixo, reboco ecológico, produção } \\
\text { com garrafas pet (cadeira, etc). }\end{array}$ \\
\hline TA3 - Tecnologias Ambientais 3 & Esgotamento ecológico e outros. \\
\hline OC - Organização de Cooperativas Ambientais & $\begin{array}{l}\text { O que são cooperativas? Direito e formação de } \\
\text { cooperativa, as redes ecológicas. }\end{array}$ \\
\hline NE - Negócios Ecológicos & $\begin{array}{l}\text { As macro e microrrelações dos negócios } \\
\text { ecológicos; princípios de negócios pelo mundo; } \\
\text { A rede de negócios ecológicos. }\end{array}$ \\
\hline Cronograma do curso & Matérias \\
\hline 1a fase mês 1 e 2 & EAQ, EP, TA1, DDHH. \\
\hline $2^{\underline{a}}$ fase mês 3 e 4 & NE, TA 2 e 3, OC. \\
\hline
\end{tabular}

\section{$4^{\text {a }}$ fase - Da fase da implantação dos negócios ecológicos}

Formação definitiva da cooperativa local, busca de links com outras cooperativas e/ou outras regiões para formar uma rede de negócios ecológicos comunitários.

\section{Da fase da implantação dos negócios ecológicos}

Onde a Natureza pode render dinheiro:

1. Produtos orgânicos certificados

2. Produtos certificados pelo selo verde

3. Adoção privada de terras para conservação

4. Compensação obrigatória para compensação ambiental

5. Pagamentos voluntários para manutenção de mananciais.

6. Formação da cooperativa de trabalhadores ecológicos.

\section{Reuniões}

Reuniões devem ser semanais cumprindo a carga de $20 \mathrm{~h}$, sendo $10 \mathrm{~h}$ em campo, em organização de dados a serem cadastrados ou planejamento.

Dias de ida a campo.

Principalmente aos sábados.

\section{Possíveis isenções fiscais para possíveis steakholders}

A função extrafiscal do tributo, visando ao comportamento humano valoriza a liberdade do contribuinte permitindo-lhe a opção pelo aumento da carga tributária ou a modificação da conduta socialmente indesejada. Ato de política fiscal - almejando-se o atendimento de fins sociais por fomentos ou desestímulos a certas ações, condutas ou atividades. Funciona como meio de indução às ações favoráveis aos fins perseguidos pelo Estado.

Nesse sentido, vários impostos, já existentes poderão tutelar a proteção ambiental como os impostos. Exemplo: sobre consumo e produção (ICMS, ISS e IPI), sobre propriedade (IPVA, IPTU e ITR) e o Imposto de Renda (IR). 


\section{Pesquisas a serem desenvolvidas}

Monitoramento da qualidade da água e do ar, verificação da qualidade alimentar da população e seu georeferenciamento; verificação dos principais problemas ambientais da população, pesquisar os problemas que envolvam cidadania e os direitos humanos; levantamento dos focos de doença; Pesquisa em economia circular e em identidade regional, pesquisa em educação física e a terceira idade.

\section{Plano de ações}

\begin{tabular}{|l|}
\hline Objetivos ou metas \\
\hline Contato com as lideranças da comunidade \\
\hline Contratar profissionais e estagiários \\
\hline Zoneamento econômico-ecológico \\
\hline Buscar dados em diferentes órgãos \\
\hline Aplicação de questionários na comunidade \\
\hline Georeferenciamento dos dados \\
\hline Mídia para a comunidade em diferentes momentos \\
\hline Desenvolvimento de workshops em permacultura \\
\hline Curso de formação profissional \\
\hline Desenvolvimento de Educação Física na praça para a terceira idade \\
\hline Qualificação de 25 pessoas como agentes ambientais comunitários \\
\hline Criação da horta(s) comunitária \\
\hline Criação da usina de reciclagem \\
\hline Criação do esgotamento ecológico \\
\hline Desenvolvimento da cooperativa de economia circular ambiental \\
\hline Desenvolvimento de grupos de apoio em DDHH, como cláusula pétrea constitucional \\
\hline Desenvolvimento de diferentes questões da permacultura \\
\hline Diferentes ações em mídia na comunidade \\
\hline Desenvolvimento de diferentes pesquisas em universidades nascidas da pesquisa \\
\hline
\end{tabular}

\section{Plano de ações (exemplo) - Cronograma}

\begin{tabular}{|l|c|c|c|c|c|c|c|c|c|c|c|c|}
\hline Plano de ações (exemplo) Cronograma & 1 & 2 & 3 & 4 & 5 & 6 & 7 & 8 & 9 & 10 & 11 & 12 \\
\hline Contato com as lideranças da comunidade & $\mathrm{X}$ & & & & & & & & & & & \\
\hline Contratar profissionais e estagiários & $\mathrm{X}$ & & & & & & & & & & & \\
\hline Pesquisas previas & $\mathrm{X}$ & & & & & & & & & & & \\
\hline Reuniões & $\mathrm{X}$ & $\mathrm{X}$ & $\mathrm{X}$ & $\mathrm{X}$ & $\mathrm{X}$ & $\mathrm{X}$ & $\mathrm{X}$ & $\mathrm{X}$ & $\mathrm{X}$ & $\mathrm{X}$ & $\mathrm{X}$ & $\mathrm{X}$ \\
\hline Zoneamento econômico-ecológico & $\mathrm{X}$ & & & & & & & & & & & \\
\hline Buscar dados em diferentes órgãos & $\mathrm{X}$ & $\mathrm{X}$ & $\mathrm{X}$ & $\mathrm{X}$ & $\mathrm{X}$ & $\mathrm{X}$ & $\mathrm{X}$ & $\mathrm{X}$ & $\mathrm{X}$ & $\mathrm{X}$ & $\mathrm{X}$ & $\mathrm{X}$ \\
\hline Aplicação de questionários na comunidade & & $\mathrm{X}$ & $\mathrm{X}$ & & & & & & & & & \\
\hline Georeferenciamento dos dados & $\mathrm{X}$ & $\mathrm{X}$ & $\mathrm{X}$ & $\mathrm{X}$ & $\mathrm{X}$ & $\mathrm{X}$ & $\mathrm{X}$ & $\mathrm{X}$ & $\mathrm{X}$ & $\mathrm{X}$ & $\mathrm{X}$ & $\mathrm{X}$ \\
\hline Curso de formação & & & & $\mathrm{X}$ & $\mathrm{X}$ & $\mathrm{X}$ & $\mathrm{X}$ & & & & & \\
\hline Mídia & & $\mathrm{X}$ & $\mathrm{X}$ & $\mathrm{X}$ & $\mathrm{X}$ & $\mathrm{X}$ & $\mathrm{X}$ & $\mathrm{X}$ & $\mathrm{X}$ & $\mathrm{X}$ & $\mathrm{X}$ & $\mathrm{X}$ \\
\hline workshops em permacultura & & $\mathrm{X}$ & $\mathrm{X}$ & & $\mathrm{X}$ & & $\mathrm{X}$ & $\mathrm{X}$ & $\mathrm{X}$ & $\mathrm{X}$ & $\mathrm{X}$ & $\mathrm{X}$ \\
\hline Educação Física para a terceira idade & & $\mathrm{X}$ & $\mathrm{X}$ & $\mathrm{X}$ & $\mathrm{X}$ & $\mathrm{X}$ & $\mathrm{X}$ & $\mathrm{X}$ & $\mathrm{X}$ & $\mathrm{X}$ & $\mathrm{X}$ & $\mathrm{X}$ \\
\hline Criação da horta(s) comunitária & & & & $\mathrm{X}$ & $\mathrm{X}$ & $\mathrm{X}$ & $\mathrm{X}$ & $\mathrm{X}$ & $\mathrm{X}$ & $\mathrm{X}$ & $\mathrm{X}$ & $\mathrm{X}$ \\
\hline $\begin{array}{l}\text { Criação do quadro de fotos para } \\
\text { monitoramento ambiental }\end{array}$ & & $\mathrm{X}$ & $\mathrm{X}$ & $\mathrm{X}$ & $\mathrm{X}$ & $\mathrm{X}$ & $\mathrm{X}$ & $\mathrm{X}$ & $\mathrm{X}$ & $\mathrm{X}$ & $\mathrm{X}$ & $\mathrm{X}$ \\
\hline Criação da usina de reciclagem (outra região) & - & - & - & - & - & - & - & - & - & - & - & - \\
\hline Criação do esgotamento ecológico (outra região) & - & - & - & - & - & - & - & - & - & - & - & - \\
\hline $\begin{array}{l}\text { Desenvolvimento da cooperativa de economia } \\
\text { circular ambiental }\end{array}$ & & & & & & & & & & & $\mathrm{X}$ & $\mathrm{X}$ \\
\hline Desenvolvimento de grupos de apoio em DDHH & & $\mathrm{X}$ & $\mathrm{X}$ & $\mathrm{X}$ & $\mathrm{X}$ & $\mathrm{X}$ & $\mathrm{X}$ & $\mathrm{X}$ & $\mathrm{X}$ & $\mathrm{X}$ & $\mathrm{X}$ & $\mathrm{X}$ \\
\hline
\end{tabular}




\section{Comunicação do projeto}

\begin{tabular}{|c|c|}
\hline Tipo de mídia & Época \\
\hline 1. Cartilhas de educação ambiental e folders & Sempre \\
\hline 2. Entrevistas & $2^{\underline{a}}$ fase \\
\hline 3. Debates e Palestras com a comunidade & Ao longo do projeto \\
\hline 4. Camisetas e bonés & 1a e $3^{\mathrm{a}}$ fases e durante o curso (comunidade) \\
\hline 5. Internet & Sempre \\
\hline
\end{tabular}

\section{Orçamento}

Este orçamento deve se basear como uma primeira etapa de uma trajetória de muitas outras, aonde o maior pensamento seja dinamizar um caminho de expansão dessa metodologia redinamizando-se por diferentes lugares gerando luminosidade a antigas áreas opacas. Nossa ideia é formar uma grande rede de negócios ecológicos comunitários, e ao mesmo tempo garantir ética, qualidade de vida e reduzir a miséria em busca da reafirmação da cultural como elemento dinamizador de mudança efetiva. Qualquer dúvida em relação ao orçamento pode ser tirada via email.

\section{Resultados}

\section{Produtos e benefícios gerados e entregues à comunidade}

Pessoas beneficiadas diretamente

- 30 idosos ambos os gêneros em atividades de educação física na praça ou comunitária (clubes, escolas etc).

- 25 pessoas qualificadas profissionalmente.

Pessoas beneficiadas indiretamente

- Espera-se beneficiar toda a comunidade com o projeto tanto com a horta comunitária como com os benefícios trazidos pelo projeto.

Mídia educativa

- Produção de material de educação ambiental local.

- Produção de material didático para: prevenção de acidentes ambientais, de direitos humanos, direito à cidadania dentre outros.

- Criação do quadro de fotos para monitoramento ambiental local.

Benefícios trazidos pela Permacultura

- Criação de uma horta comunitária com dimensão mínima de (30 x 20 m) que atenderá proporcionalmente a população local como determinado pelo último congresso global de meio ambiente; Aprendizado: tinta ecológica para pintura de casas, como montar uma usina de reciclagem, técnicas de reciclagem e reaproveitamento do lixo, reboco ecológico, produção com garrafas pet (cadeira, etc), esgotamento ecológico, geração de energia da biomassa e redução de resíduos de esgoto, xampu e sabonete ecológico e outros.

\section{Aprendizado teórico para a comunidade gerado pela permacultura}

- Aulas teóricas de diferentes questões como: geração de energia da biomassa; redução de resíduos de esgoto; Reciclagem de lixo e outras diferentes técnicas (curso e workshop). Aprendizado com prática em sala de aula. Exemplo: - sabonete ecológico, - reboco ecológico, - xampu ecológico, trabalhos com garrafas PET (cadeiras etc).

Número de pessoas atendidas no curso -

Habitantes não locais 5, locais 20 


\section{Conclusão}

Apresentamos um projeto de gestão territorial que não se limita a ótica fragmentada clássica, mais que, possui uma visão de totalidade tornando possível a compreensão das interconectividades e da complexidade que formam a realidade de uma região específica.

Neste sentido buscamos conhecer as lógicas territoriais de forma a entender e eliminar as grandes mazelas que se realizam na sociedade. Para isso diferentes estratégias singulares tendem a se desenvolver. Estratégia como a pedagógica, não ocorrerá apenas no curso de formação de agentes ambientais locais, mais também em workshops, folders, em debates e com o contato dos estagiários com a comunidade. Esse mecanismo se relaciona a integração comunidade, universidade e sociedade civil, fato considerado fundamental para alicerçar a estrutura desta construção.

A gestão, que visa a crescer exponencialmente formando uma rede de negócios ecológicos, entende a importância de superar as barreiras geográficas de um bairro, comunidade ou mesmo município tendo em vista a necessidade da criação de elos que busquem sintropia entre os lugares. Essa tendência objetiva garantir integração ajuda e troca de experiências entre as comunidades envolvidas e se materializará na formação da rede de negócios ecológicos.

Esperamos que este pequeno debate teórico e metodológico apresentado possa ajudar as empresas a traçarem um novo caminho integrando-se ás comunidades que são seu público alvo. A participação do setor produtivo, gerando qualidade de vida e produtividade para as comunidades pesquisadas é um caminho possível na evolução social de países periféricos como o Brasil.

Esta metodologia apresenta a sua realidade a luz de um novo debate que surge na ciência pela obviedade da necessidade de transformação da sociedade em que vivemos. Propomos assim, uma alteração no paradigma das empresas se associando a uma nova forma de leitura da realidade, a realidade quântica.

\section{Conflito de interesses}

O autor declara não haver conflito de interesses.

\section{Referências}

ABNT - Associação Brasileira de Normas Técnicas. ABNT NBR ISO 26000: Diretrizes sobre responsabilidade social. Rio de Janeiro: ABNT, 2010.

Atlan, H. Entre o cristal e a fumaça: ensaios sobre a organização do ser vivo. Rio de Janeiro: Jorge Zahar, 1992.

Brasil. Decreto no 4.297, de 10 de julho de 2002. Regulamenta o art. 9o, inciso II, da Lei no 6.938, de 31 de agosto de 1981, estabelecendo critérios para o Zoneamento Ecológico-Econômico do Brasil-ZEE, e dá outras providências. Disponível em: <http://www.planalto.gov.br/ccivil_03/decreto/2002/D4297.htm>. Acesso em: 23 abr. 2020.

Brasil. Lei no 6.938, de 31 de agosto de 1981. Dispõe sobre a Política Nacional do Meio Ambiente, seus fins e mecanismos de formulação e aplicação, e dá outras providências. Disponível em: <http://www.planalto.gov.br/ccivil_03/LEIS/L6938compilada.htm>. Acesso em: 23 abr. 2020. 
Brasil. Lei no 12.651, de 25 de maio de 2012. Dispõe sobre a proteção da vegetação nativa; altera as Leis $\mathrm{n}^{\mathrm{os}}$ 6.938, de 31 de agosto de 1981, 9.393, de 19 de dezembro de 1996, e 11.428, de 22 de dezembro de 2006; revoga as Leis nos 4.771, de 15 de setembro de 1965, e 7.754, de 14 de abril de 1989, e a Medida Provisória no 2.166-67, de 24 de agosto de 2001; e dá outras providências. Disponível em: <http://www.planalto.gov.br/ccivil_03/_ato20112014/2012/lei/L12651compilado.htm>. Acesso em: 23 abr. 2020.

Camargo, L. H. R. A ruptura do meio ambiente: conhecendo as mudanças ambientais do planeta através de uma nova percepção de ciência: a geografia da complexidade. Rio de Janeiro: Bertrand, 2005.

Camargo, L. H. R. Projeto Botafogo Razão Social. Registrado no escritório de Direitas Autorais da Cidade do Rio de Janeiro, sob número 022774, 2015.

Capra, F.; Steindl-Rast, D. Pertencendo ao Universo: explorando as fronteiras da Ciência e da espiritualidade. 10. ed. São Paulo: Cultrix, 1991.

Davies, P. 0 enigma do tempo: a revolução iniciada por Einstein. Rio de janeiro: Ediouro, 1999.

Drew, D. Processos interativos homem-meio ambiente. 3. ed. Rio de Janeiro: Bertrand Brasil, 2002.

Hawking, S. Uma breve história do tempo. Rio de Janeiro: Intrinseca, 2015.

Jung, C. Psicologia do inconsciente. Petrópolis: Vozes, 1980.

Kant, I. Crítica da razão pura. São Paulo: Nova Cultural, 1999.

Kelly, M. Capitalismo alternativo e o futuro dos negócios: construindo uma economia que funcione para todos. São Paulo: Cultura, 2016.

Kuhn, T. A estrutura das revoluções científicas. São Paulo: Perspectiva, 1970.

Lao-Tsé. Tao Te Ching: o livro que revela a Deus. São Paulo: Martin Claret, 2004.

MMA - Ministério do Meio Ambiente. Programa ZEE Brasil. 2019. Disponível em: <https://www.mma.gov.br/endere\%C3\%A7os-importantes/item/7531-programa-zeebrasil>. Acesso em: 23 abr. 2020.

Moreira, R. A Geografia serve para desvendar máscaras sociais. In: Moreira, R. (Org). Geografia teoria e crítica. Petrópolis: Vozes, 1982.

Morin, E. 0 método I: a natureza da Natureza. Lisboa: Europa-América, 1977.

Newton, I. Princípios matemáticos da Filosofia Natural. São Paulo: Nova Cultural, 1987. (Coleção Os Pensadores).

Ostrom, E. Governing the commons: The evolution of institutions for colletive action. Cambridge: Cambridge University Press, 1990.

Prigogine, I. 0 nascimento do tempo. Lisboa: Biblioteca 70, 2008.

Prigogine, I.; Stengerls, I. A nova aliança: metamorfose da Ciência. Brasília: UNB, 1997.

Prigogine, I.; Stengerls, I. Order out of chaos: mans new dialogue with Nature. New York: Bantam Books, 1984.

Santos, M. Espaço \& método. São Paulo: Nobel, 1997a.

Santos, M. A natureza do espaço: técnica e tempo, razão e emoção. São Paulo: HUCITEC, $1997 b$. 
Smilga, V. A relatividade e o homem. Lisboa: Presença, 1966.

Souza, M. L. Mudar a cidade: uma introdução crítica ao planejamento e à gestão urbana. 2. ed. Rio de Janeiro: Bertrand Brasil, 2001.

Vitte, A. C.; Dutra-Gomes, R. Geossistemas e complexidade: sobre hierarquias e diálogos $\begin{array}{lllll}\text { entre os conhecimentos. } & \text { RA'EGA, } & \text { v. 42, } & \text { p. 149-164, }\end{array}$ https://doi.org/10.5380/raega.v42i0.46746

Weil, P.; D'Ambrosio, U.; Crema, R. Rumo à nova transdisciplinaridade: sistemas abertos do conhecimento. São Paulo: Summus, 1993.

Whitehead, A. N. Process and reality: An essay in Cosmology. Mind, v. 39, n. 156, p. 466475, 1930. 